\title{
The Relationship Between Social Determinants of Health and Functional Capacity in Adult Primary Care Patients With Multiple Chronic Conditions
}

\author{
Levi N. Bonnell, MPH, Abigail M. Crocker, PhD, Kathleen Kemp, MD, and \\ Benjamin Littenberg, $M D$
}

Purpose: Social determinants of health (SDoH) including insecure access to food, housing, and financial resources are critical threats to overall health. We sought to examine this relationship among adult primary care patients with multiple chronic conditions.

Methods: We obtained cross-sectional data on 2763 adults with chronic medical and behavioral conditions or greater than 2 chronic medical conditions from a survey of participants in Integrating Behavioral Health and Primary Care, a multicenter randomized trial.

Results: The prevalence of 1 or more insecurities was reported in 29\% of participants, including food (13\%), housing (3\%), or financial (25\%). Functional capacity ranged from 2.74 to 9.89 metabolic equivalents (METs) (median, 6.05). The distribution of functional capacity was significantly lower for those with any 1 or more SDoH than for those without. Each insecurity independently affected the functional capacity in multivariable analysis.

Conclusions: Among primary care patients with chronic conditions, SDoH are associated with poorer functional capacity, independent of other social and demographic factors. Primary care offers a promising, if underused, opportunity to intervene in SDoH. There is a need for future studies to explore the role of screening and intervention by primary care providers to mitigate or prevent SDoH. (J Am Board Fam Med 2021;34:688-697.)

Keywords: Chronic Disease, Cross-Sectional Studies, Multiple Chronic Conditions, Primary Health Care, Social Determinants of Health, Social Problems, Surveys and Questionnaires

\section{Introduction}

Social determinants of health $(\mathrm{SDoH})$, including food insecurity, housing instability, and financial hardship, are common in the United States, ${ }^{1}$ disproportionately impact vulnerable populations, and are associated with poor health outcomes. One in 8 US households are food insecure, ${ }^{2} 0.2 \%$ of US adults are homeless, ${ }^{3}$ and

Submitted 7 January 2021; revised 25 February 2021; accepted 11 March 2021.

From University of Vermont, Burlington, VT (LNB, AMC, KK, BL); Clinton Medical Associates, University of Rochester, Rochester, NY (LNB, AMC, KK, BL).

Funding: This work was funded through a PatientCentered Outcomes Research Institute (PCORI) Award (PCS-1409-24372). The views, statements, and opinions presented are solely the responsibility of the authors and do not necessarily represent the views of PCORI or its Board of Governors or Methodology Committee.

Corresponding author: Levi N. Bonnell, MPH, 89 Beaumont Ave S459, Burlington, VT 05405 (E-mail: levi. bonnell@med.uvm.edu).
$12 \%$ are living in poverty. ${ }^{4}$ Food, housing, and financial insecurities are more common among women, African Americans, younger adults, and those with lower education or chronic conditions. ${ }^{5-9}$ Food insecurity is independently associated with obesity, ${ }^{10}$ peripheral artery disease, ${ }^{11}$ hypertension, ${ }^{12}$ hyperlipidemia, ${ }^{12}$ diabetes, ${ }^{13}$ medication underuse,${ }^{14}$ and overall poor health. ${ }^{15-17}$ Both food insecurity and housing instability are associated with sleep disorders, ${ }^{18,19}$ social isolation, ${ }^{20}$ cardiovascular disease, ${ }^{7}$ and poor overall physical and mental health. ${ }^{18,21-23}$ There is extensive evidence of the negative effects of financial hardship and poverty on health and access to care. ${ }^{24}$ Poor health outcomes, financial hardship, and food insecurity are worse in rural areas than urban areas, ${ }^{25-27}$ although mechanisms differ.

Poor functional capacity is a common physical limitation among the chronically ill and a major risk factor for mortality. ${ }^{28-30}$ Exercise capacity, a measure of 
functional capacity, is the maximum sustainable amount of physical exertion. It is typically measured by the amount of oxygen consumed during maximal exercise, often presented in metabolic equivalents (METs). One MET is the amount of oxygen consumed at rest $(3.5 \mathrm{~mL} \mathrm{O} 2$ per $\mathrm{kg}$ body weight $\times$ $\mathrm{min}) .{ }^{31}$ METs can also be estimated from questionnaires such as the Duke Activity Status Index (DASI). ${ }^{32,33}$ Like other aspects of functional status, functional capacity may influence access to food, housing, and financial resources, often through employment. Conversely, poor diet, unstable housing, poverty, and inability to access care and medications may influence functional capacity. These relationships are often exacerbated among chronically ill populations. $^{7}$ Despite evidence of a relationship between $\mathrm{SDoH}$, cardiovascular disease, and other health outcomes, the relationship between $\mathrm{SDoH}$ and functional capacity has yet to be examined.

Building on prior literature, we sought to characterize the relationship of $\mathrm{SDoH}$, in particular food insecurity, housing instability, and financial hardship, with functional capacity, among highly vulnerable adult primary care patients with chronic medical and behavioral conditions. We hypothesized that the presence of 1 or more SDoH will be associated with reduced functional capacity. Further, we hypothesized that food insecurity, housing instability, and financial hardship will each be independently associated with reduced functional capacity.

\section{Methods}

Our primary analysis modeled functional capacity in relation to the presence of any 1 or more insecurities. Our secondary analysis characterized the independent effects of each insecurity (food, housing, and financial) on functional capacity. Finally, a tertiary analysis modeled functional capacity as a function of the total number of SDoH (0 to 3).

\section{Data and Setting}

We used baseline survey results from Integrating Behavioral Health and Primary Care, a multicenter randomized study of chronically ill primary care patients from 2016 to 2021, described in detail elsewhere. ${ }^{34}$ Baseline data were collected before the COVID-19 pandemic. Data were collected from 4023 adults with multiple chronic conditions (arthritis, obstructive lung disease including emphysema, chronic bronchitis or asthma, nongestational diabetes, heart disease manifested as heart failure or hypertension, mood disorder [anxiety or depression], chronic pain [including headache, migraine, neuralgia, fibromyalgia, or chronic musculoskeletal pain], insomnia, irritable bowel syndrome, and substance misuse [substance use disorder, tobacco use, or problem drinking]) from 44 primary care practices across 13 states. To be eligible for this study, participants needed to have either at least 1 chronic medical and 1 behavioral health condition or greater than 2 chronic medical conditions. Participants also needed to be an active patient of a participating study practice as evidenced by at least 2 visits in a period of 24 months for any purpose, including at least 1 in the most recent 6 months. The presence or absence of each qualifying condition, and the dates of office visits, were determined by review of electronic health record visit data, problem lists, medication lists, and laboratory results.

The primary outcome was functional capacity measured by the DASI, ${ }^{32}$ a 12 -item questionnaire that assesses the ability to do self-care, housework, sports, and other activities. The DASI generates an estimated maximal oxygen consumption, which correlates with results of treadmill testing ${ }^{31-33}$ and long-term health outcomes in chronically ill patients. ${ }^{29,35,36} \mathrm{We}$ converted the DASI to METs (0 to 9.89), where higher METs indicate better functional capacity.

SDoH was captured using 4 yes/no questions (see Table 1). The primary predictor variable was a binary indicator of the presence of any 1 or more of the 3 insecurities (answered yes to any of the 4 questions in Table 1). Food insecurity and financial hardship were captured using 1 question while housing instability was captured using 2 questions. A count variable was created representing the number of SDoH insecurities (food, housing, or financial) present (0 to 3).

Potential covariates associated with both SDoH and functional capacity were chosen based on clinical knowledge and prior literature. Person-level demographic covariates included age, sex (male vs female), race (white, black or African American, Asian, other), ethnicity (Hispanic vs non-Hispanic), marital status (married vs not), employment status (employed vs not), annual household income (in 7 categories), and education (in 6 categories). We also included medical and behavioral conditions (present vs absent) as potential covariates in the model including arthritis, 
Table 1. Social Determinants of Health

\begin{tabular}{|c|c|c|}
\hline Domain & Question & Answer \\
\hline Food insecurity & $\begin{array}{l}\text { In the past } 12 \text { months, did you ever eat less than you felt you should } \\
\text { because there wasn't enough food? }\end{array}$ & Yes/No \\
\hline Housing instability & $\begin{array}{l}\text { In the past } 12 \text { months, did you ever have to sleep at a friend or family } \\
\text { member's house because you had no place else to live? } \\
\text { In the past } 12 \text { months, did you ever have to sleep outside, in a public place, } \\
\text { or in a shelter because you had no place else to live? }\end{array}$ & Yes to either/no to both \\
\hline Financial hardship & $\begin{array}{l}\text { In the past } 12 \text { months, did you ever not have enough money to pay your } \\
\text { basic living expenses (mortgage, rent, utilities, medicines, etc.)? }\end{array}$ & Yes/No \\
\hline
\end{tabular}

obstructive lung disease, nongestational diabetes, heart disease, mood disorder, chronic pain, insomnia, irritable bowel syndrome, substance misuse, and medication adherence measured by the Morisky Medication Adherence Scale. ${ }^{37}$

Each participant's home address was mapped, and various neighborhood covariates were identified for potential inclusion in the final models. The Social Deprivation Index ${ }^{38}$ (SDI) is a census tractlevel composite measure of deprivation based on income, education, employment, housing, singleparent household, and access to transportation. Census tract urban/rural status was based on Rural Urban Commuting Areas, ${ }^{39}$ which are derived from population density, urbanization, and daily commuting. Population density was assigned from their home census tract.

Potential practice-level covariates included information on behavioral health services, specialty, volume of encounters, type (nonprofit, academic, private), percent of patient population on Medicare, and county-level demographic measures (age, sex, race, income, employment, education).

\section{Statistical Analysis}

We used Wilcoxon rank-sum tests to compare the unadjusted distribution of functional capacity between those with and without 1 or more $\mathrm{SDoH}$. Multilevel linear regression models were used to estimate the mean difference in functional capacity in METs by SDoH (with its 95\% CI). Practice was included as a random intercept to account for correlation of patient-level measures within the primary care practice in which they were recruited. All predictors and covariates were included as fixed effects. The primary analysis modeled the effect of any 1 or more $\mathrm{SDoH}$ on functional capacity. Secondary analyses were independently performed for each of food, housing, and finance and the total number of insecurities. We repeated the main analysis while restricting the sample to those who met criteria for specific subgroups.

For the sake of parsimony and model reduction, covariates (described above) were included in the final model only if they changed the coefficient of SDoH on functional capacity by more than $\pm 10 \%$ in a model containing only 2 predictors (SDoH and the covariate). All tests were 2-tailed and the threshold for statistical significance was $\alpha=0.05$. Stata 16.1 (StataCorp LP, College Station, Texas) was used for data management and statistical analysis. The University of Vermont Institutional Review Board approved this study.

\section{Results}

Two thousand seven hundred sixty-three participants were available for analysis. One or more insecurities were reported by $28 \%$. Financial hardship was the most prevalent $(25 \%)$, followed by food insecurity (13\%) and housing instability (3\%). Most participants with an insecurity only had 1 (19\%), $8 \%$ had 2 insecurities, and $1 \%$ had 3 insecurities. Participants with any insecurity tended to be younger, black or other race, female, not married, not working, lower income, less educated, and living in socially deprived, densely populated areas compared with those without an insecurity. Most chronic diseases were more prevalent among participants with insecurities (see Table 2). Functional capacity ranged from 2.74 to 9.89 METs (median, 6.05; interquartile range, 4.73-7.99).

The final sample had missing information on $249(8 \%)$ of records, of which 229 were missing data on METs and 64 were missing information on some or all of the SDoH. In the final multivariable models, there was $12 \%$ to $13 \%$ missing data. The records with missing data that were excluded from the final models did not significantly differ from those with complete data in terms of age, sex, race, ethnicity, functional capacity, and SDoH. 
Table 2. Characteristics of Population Stratified by Any One or More Social Determinants of Health (SDoH) Insecurity $(\mathrm{n}=\mathbf{2 7 6 3})$

\begin{tabular}{|c|c|c|}
\hline & $\begin{array}{l}1 \text { or More Insecurityn (\%) } \\
\text { or Mean } \pm \text { SD }\end{array}$ & $\begin{array}{c}\text { No Insecuritiesn (\%) or } \\
\text { Mean } \pm \text { SD }\end{array}$ \\
\hline \multicolumn{3}{|l|}{ Sample size } \\
\hline $\mathrm{n}$ & 792 & 1971 \\
\hline \multicolumn{3}{|l|}{ Subject characteristics } \\
\hline Age, years & $55 \pm 13$ & $64 \pm 13$ \\
\hline Sex (male vs female) & $264(34 \%)$ & $736(38 \%)$ \\
\hline \multicolumn{3}{|l|}{ Race } \\
\hline White & $538(68 \%)$ & $1543(78 \%)$ \\
\hline Black or African American & $132(17 \%)$ & $189(10 \%)$ \\
\hline Asian & $13(2 \%)$ & $73(4 \%)$ \\
\hline Other & $109(14 \%)$ & $166(8 \%)$ \\
\hline Ethnicity (Hispanic vs non-Hispanic) & $106(14 \%)$ & $168(9 \%)$ \\
\hline Married or living as married versus other & $244(31 \%)$ & $1082(55 \%)$ \\
\hline Employed (full time, part time, or student) & $233(30 \%)$ & $676(35 \%)$ \\
\hline \multicolumn{3}{|l|}{ Annual household income } \\
\hline$<\$ 15,00$ & $437(56 \%)$ & $403(21 \%)$ \\
\hline$\$ 15,000-\$ 29,999$ & $196(25 \%)$ & $408(21 \%)$ \\
\hline$\$ 30,000-\$ 44,999$ & $68(9 \%)$ & $256(13 \%)$ \\
\hline$\$ 45,000-\$ 59,999$ & $30(4 \%)$ & $180(9 \%)$ \\
\hline$\$ 60,000-\$ 74,999$ & $25(3 \%)$ & $184(10 \%)$ \\
\hline$\$ 75,000-\$ 99,999$ & $16(2 \%)$ & $193(10 \%)$ \\
\hline$>\$ 100,000$ & $9(1 \%)$ & $301(16 \%)$ \\
\hline \multicolumn{3}{|l|}{ Education } \\
\hline Less than 9th grade & $35(4 \%)$ & $65(3 \%)$ \\
\hline 9th to 12 th grade, no diploma & $100(13 \%)$ & $152(8 \%)$ \\
\hline High school graduate (including GED) & $395(50 \%)$ & $747(38 \%)$ \\
\hline Associate degree & $119(15 \%)$ & $320(16 \%)$ \\
\hline Bachelor's degree & $86(11 \%)$ & $353(18 \%)$ \\
\hline Graduate or professional degree & $57(7 \%)$ & $330(17 \%)$ \\
\hline \multicolumn{3}{|l|}{ Chronic conditions } \\
\hline Arthritis & $332(42 \%)$ & $826(42 \%)$ \\
\hline Asthma & $219(28 \%)$ & $389(20 \%)$ \\
\hline Obstructive lung disease & $177(16 \%)$ & $333(12 \%)$ \\
\hline Chronic pain & $701(89 \%)$ & $1620(82 \%)$ \\
\hline Non-gestational diabetes & $392(50 \%)$ & $869(44 \%)$ \\
\hline Heart disease & $656(83 \%)$ & $1728(88 \%)$ \\
\hline Irritable bowel syndrome & $40(5 \%)$ & $78(4 \%)$ \\
\hline Lung disease & $322(41 \%)$ & $585(30 \%)$ \\
\hline Mood disorder & $581(73 \%)$ & $1188(60 \%)$ \\
\hline Insomnia & $216(27 \%)$ & $477(24 \%)$ \\
\hline Substance use disorder & $366(33 \%)$ & $472(17 \%)$ \\
\hline Tobacco use & $227(29 \%)$ & $283(14 \%)$ \\
\hline Unhealthy alcohol use & $82(10 \%)$ & $101(5 \%)$ \\
\hline Total chronic conditions & $6 \pm 2$ & $5 \pm 2$ \\
\hline \multicolumn{3}{|c|}{ Medication adherence (higher indicates worse adherence) } \\
\hline \multicolumn{3}{|l|}{ Morisky Medication Adherence Scale } \\
\hline 0 & $229(29 \%)$ & $992(51 \%)$ \\
\hline 1 & $159(20 \%)$ & $425(22 \%)$ \\
\hline 2 & $236(30 \%)$ & $392(20 \%)$ \\
\hline
\end{tabular}




\begin{tabular}{lll}
\hline & $\begin{array}{c}1 \text { or More Insecurityn (\%) } \\
\text { or Mean } \pm \text { SD }\end{array}$ & $\begin{array}{c}\text { No Insecuritiesn (\%) or } \\
\text { Mean } \pm \text { SD }\end{array}$ \\
\hline 3 & $97(13 \%)$ & $95(5 \%)$ \\
4 & $64(8 \%)$ & $47(2 \%)$ \\
Neighborhood characteristics & & $50 \pm 28$ \\
$\quad$ Social deprivation index (higher indicates more deprivation) & $63 \pm 26$ & $1542(79 \%)$ \\
Urban & $651(85 \%)$ & $3876 \pm 7755$ \\
Population density, persons per square mile & $4340 \pm 4818$ & $6.6 \pm 2.0$ \\
Functional capacity & & 6.6 \\
Metabolic equivalents (METs) & $5.6 \pm 1.8$ & $5.1,8.3$ \\
Median, METs & 5.1 & $4.4,6.7$ \\
Interquartile range $\left(25^{\text {th }}, 75^{\text {th }}\right.$ percentile), METs & & \\
\hline
\end{tabular}

SD, standard deviation.

The unadjusted effect of any or more $\mathrm{SDoH}$ on functional capacity was $-0.88 \mathrm{METs}$ ( $95 \% \mathrm{CI},-1.02$, $-0.74 ; P<.001$; see Figure 1). Age, marital status, income, total count of chronic conditions, and census tract SDI all modified this coefficient by more than $10 \%$ and were included in the final model. In a multivariate analysis, the effect of any $\mathrm{SDoH}$ was -0.62 METs (95\% CI, $-0.78,-0.46 ; P<.001$; see Figure 1 ).

The unadjusted effects of food, housing, and financial insecurities on functional capacity were -0.75 METs (95\% CI, $-0.97,-0.53 ; P<.001),-0.60$ METs (95\% CI, $-1.00,-0.20 ; P=.003)$, and -0.84 METs (95\% CI, $-1.01,-0.67 ; P<.001)$, respectively. Age, marital status, income, education, and total count of medical and behavioral conditions all modified the coefficient by more than $10 \%$ and were included in all 3 models. In addition to these variables, mood disorder and census tract SDI were included in the final food insecurity mode; urban/rural status, population density, mood disorder, and arthritis were included in the housing instability model; and census tract SDI was included in the financial hardship model. In multivariable models, food, financial, and housing insecurities were associated with a reduction in functional capacity of -0.48 METs (95\% CI, $-0.68,-0.27, P<.001),-0.44$ METs (95\% CI, $-0.81,-0.08, P=.02)$, and -0.59 METs (95\% CI, $-0.76,-0.43, P<.001)$, respectively (see Table 3 \& Figure 2).

Figure 1. Difference in functional capacity associated with any 1 or more Social Determinants of Health (SDoH) insecurity. Regression coefficient and 95\% CI for the mixed linear regression with and without adjustment for all potential confounders that met the $\mathbf{1 0} \%$ inclusion criteria. The vertical line at zero represents a null association. Abbreviation: CI, confidence interval.

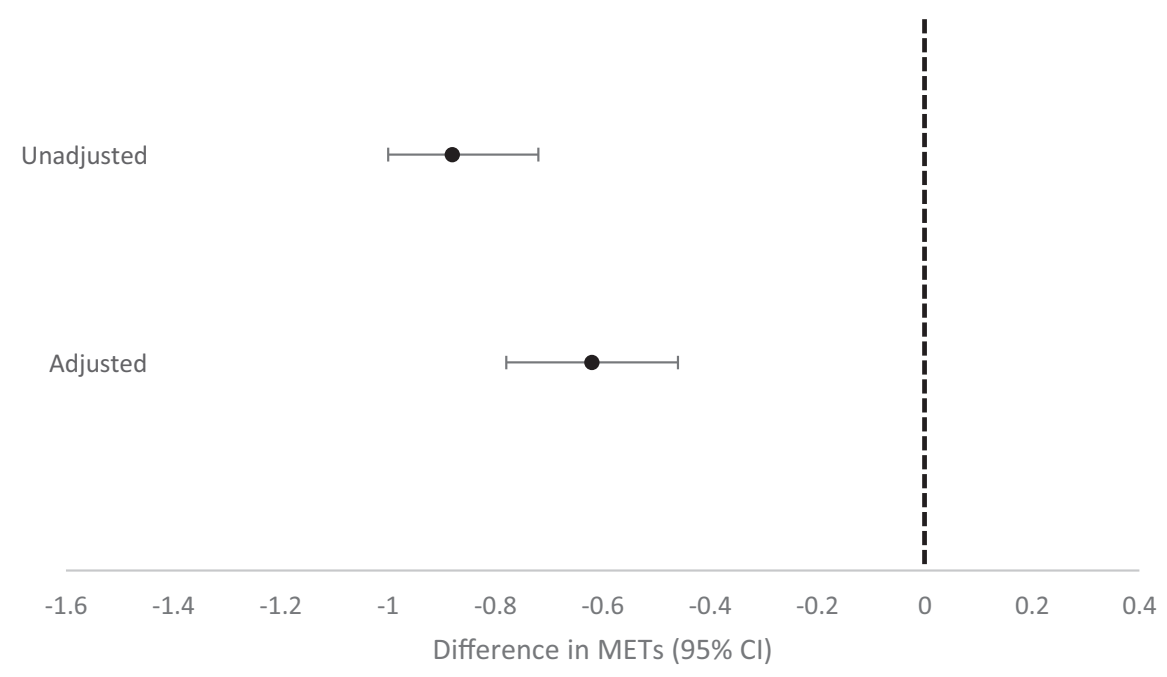


Table 3. Univariate and Multivariable Regression Results

\begin{tabular}{|c|c|c|c|c|c|c|}
\hline Insecurities & Unadjusted Effect & $95 \% \mathrm{CI}$ & $P$ & Adjusted Effect & $95 \% \mathrm{CI}$ & $P$ \\
\hline Any 1 or more* & -0.88 & $-1.02,-0.74$ & $<0.001$ & -0.62 & $-0.78,-0.46$ & $<0.001$ \\
\hline Food $^{\dagger}$ & -0.75 & $-0.97,-0.53$ & $<0.001$ & -0.48 & $-0.68,-0.27$ & $<0.001$ \\
\hline Housing $^{\ddagger}$ & -0.60 & $-1.00,-0.20$ & 0.003 & -0.44 & $-0.81,-0.08$ & 0.02 \\
\hline Financial $^{\S}$ & -0.84 & $-1.01,-0.67$ & $<0.001$ & -0.59 & $-0.76,-0.36$ & $<0.001$ \\
\hline Number of insecurities $(0 \text { to } 3)^{\S}$ & -0.51 & $-0.61,-0.41$ & $<0.001$ & -0.38 & $-0.48,-0.28$ & $<0.001$ \\
\hline
\end{tabular}

*Confounder list: age, marital status, income, count of chronic conditions, Social Deprivation Index (SDI).

${ }^{\dagger}$ Confounder list: age, marital status, income, education, mood disorder, count of chronic conditions, SDI.

${ }^{\ddagger}$ Confounder list: age, marital status, income, education, mood disorder, arthritis, count of chronic conditions, urban, population density.

${ }^{\S}$ Confounder list: age, marital status, income, education, count of chronic conditions, SDI.

CI, confidence interval.

The number of insecurities had a dose-response relationship with functional capacity. In unadjusted models, each additional insecurity reduced functional capacity by -0.51 METs $(95 \% \mathrm{CI},-0.61,-0.41$, $P<.001)$. Age, marital status, income, total count of chronic conditions, and census tract SDI all modified the coefficient by more than $10 \%$ and were included in the final model. In multivariable analysis, each additional insecurity resulted in a reduction in functional capacity of -0.38 METs $(95 \% \mathrm{CI},-0.48,-0.28$, $P<.001$; see Table 3 ).

\section{Discussion}

We used a cross section of patient-reported surveys collected from a multicenter randomized trial of adult primary care patients with multiple chronic conditions to investigate the relationship between $\mathrm{SDoH}$ and functional capacity. We found that the presence of 1 or more insecurities resulted in a loss of 0.62 METs or roughly $10 \%$ of total functional capacity. This is roughly equivalent to being able to walk briskly (3.4 MPH) versus walking at a leisurely pace (2.5 MPH). We also found that food insecurity, housing instability, financial hardship, and the total number of insecurities were each independently associated with functional capacity.

Our findings are consistent with literature showing that SDoH negatively affects health, especially for younger age groups, females, and those with lower education and more chronic illnesses..$^{5-8}$ Previous studies have shown food insecurity, housing instability, and financial hardship were related to functional disease and lung disease but not

Figure 2. Difference in functional capacity associated with food insecurity, housing instability, and financial hardship. Regression coefficient $(\beta)$ and $95 \%$ CI for the mixed linear regression with adjustment for all potential confounders. The vertical line at 0.00 represents a null association. Abbreviation: CI, confidence interval.

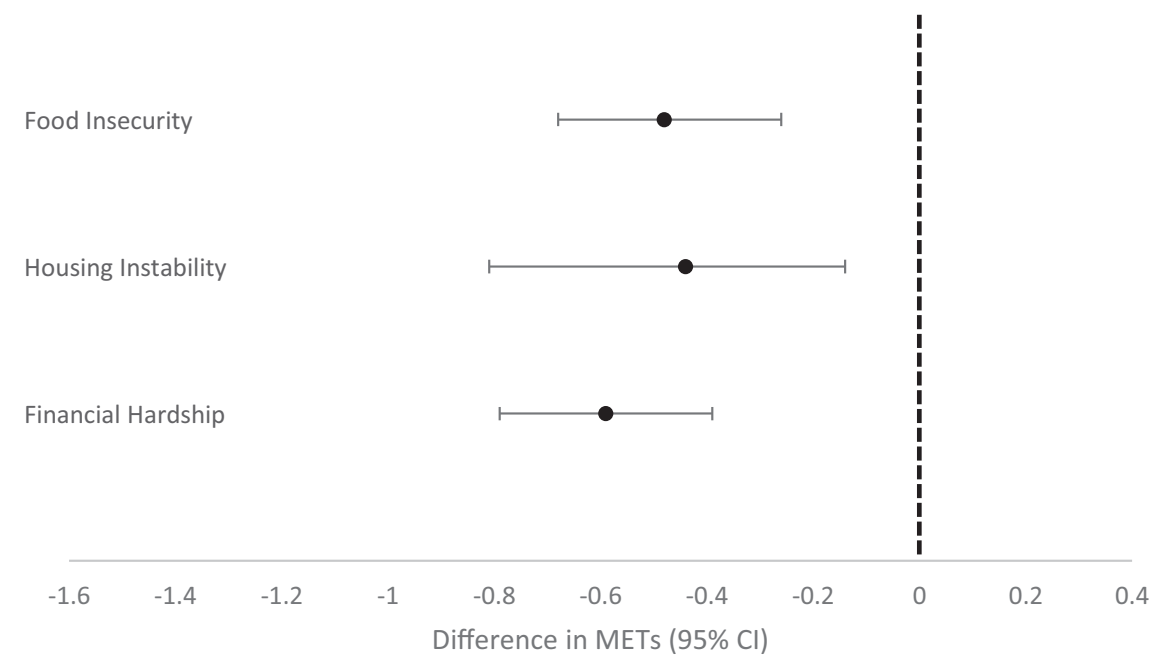


stroke. ${ }^{7}$ Further, SDoH are associated with behavioral and biomedical risk factors for cardiovascular disease. ${ }^{40}$ This study expands on these findings by confirming this association among primary care patients with multiple chronic conditions and investigating the specific functional outcome of functional capacity.

Improving functional capacity has the potential to help improve physical activity and maintain independence and aging in place for older adults, reduce health care costs, and improve quality of life. Because we saw an association between $\mathrm{SDoH}$ and functional capacity in this population, we posit that improving SDoH (whether it be food, housing, or financial) could potentially improve functional capacity. Future longitudinal studies should address this question to confirm a causal link.

The mechanism of the association between $\mathrm{SDoH}$ and functional capacity is complex. Food insecurity can reduce consumption and change the foods eaten. ${ }^{41}$ Cheaper, energy-dense food tends to be higher in calories, sugars, and fats ${ }^{42,43}$ and may contribute to the development of chronic diseases such as diabetes and hypertension, ${ }^{12,13}$ which can lead to reduction in functional capacity. Food insecurity is associated with decreased physical activity, potentially related to conserving energy. ${ }^{44}$ Housing instability and financial hardship can reduce access to care and medications, leading to chronic diseases and poor functional capacity. Another commonly proposed mechanism is that $\mathrm{SDoH}$ increases stress, resulting in high cortisol levels that can lead to heart disease and poor functional capacity. ${ }^{45}$

The prevalence of food insecurity in our sample was similar to national estimates, but housing instability was higher than estimates of homelessness and financial hardship was higher than national estimates of poverty. These findings could be unique to our sample of chronically ill adults or due to the various ways housing and financial insecurity are measured and defined. Food insecurity is ubiquitously defined as "limited or uncertain availability of safe and nutritionally adequate food." ${ }^{46}$ In our sample, the prevalence of food insecurity was $11 \%$ compared with an estimated $12 \%$ in the general US population. ${ }^{2}$ There are, however, no standard definitions for housing instability or financial insecurity.

Housing instability has variously been defined as frequent moves, difficulty paying rent, spending more than $50 \%$ of income on rent, overcrowding, and number of evictions. ${ }^{47,48}$ In our survey, housing instability is comparable to homelessness and significantly higher than national averages $(3 \%$ compared with $0.2 \%$ ), perhaps due to the population being chronically ill and older.

Similarly, financial hardship has been defined directly in terms of consumption (as in our question) or indirectly in terms of income. The prevalence of financial hardship was $24 \%$ in our sample compared with national poverty estimates (12\%). Our financial hardship question focused on difficulties in paying for life necessities, which may occur more frequently than poverty based on income. Alternatively, our population may suffer more financial hardship than the general population due to chronic illnesses.

Previous studies have shown that individuals with food insecurity, housing instability, and financial hardship are more likely to have access to care problems. ${ }^{7,47}$ However, our population is unique in that participants have evidence of access to care, suggesting different mechanisms are in play. Perhaps this chronically ill population prioritizes access to care over other necessities such as food or housing. Access to care alone may not be enough to combat SDoH challenges and related sequelae.

Race and structural racism are well documented to be associated with $\mathrm{SDoH}$ and health inequities. ${ }^{49-51}$ Our findings indicate that not only is SDoH associated with function but the effects of $\mathrm{SDoH}$ on functional capacity exist above and beyond those mediated through race. In other words, SDoH and race seem not to be proxies for each other. To improve patient functional status and quality of life, it may be important to address SDoH and racism jointly.

This study has important limitations. Although the data were collected from patients with chronic conditions from diverse parts of the country, the results may not be generalizable to other populations and settings, such as those without access to care. Second, because this is a secondary analysis, it used a limited definition of SDoH. We did not have information on transportation challenges, violence, the built environment, or social justice challenges. However, we did obtain robust data on the $3 \mathrm{SDoH}$ that were measured. Third, much of the data, notably the estimates of functional capacity, were self-reported. However, the DASI has been validated multiple times, including in chronically ill patients. ${ }^{29,35,36}$ Fourth, the cross-sectional nature 
of the study limits causal inference. For instance, although these data support the hypothesis that $\mathrm{SDoH}$ impacts functional capacity, they are also consistent with the reverse (functional capacity determines SDoH). Although we controlled for several potential confounding influences, we cannot eliminate the possibility of an unmeasured confounder. For instance, we did not have data on health insurance. However, all participants received care, indicating good access. Finally, data were missing from $13 \%$ of records in the final models. Fortunately, these records did not significantly differ by SDoH, functional capacity, or demographics from those that were included.

Primary care offers a promising, if underused, opportunity to intervene in SDoH. Although primary care physicians understand that social factors influence health, many avoid asking about them, ${ }^{52}$ and many primary care practices have not invested in developing platforms to address $\mathrm{SDoH} .{ }^{53}$ Nonetheless, strategies to address SDoH in primary care are emerging. ${ }^{54,55}$ There is a need for future studies to explore the role of screening and intervention by primary care providers to mitigate or prevent $\mathrm{SDoH}$.

This is the first analysis of $\mathrm{SDoH}$ and functional capacity. It shows that the presence of 1 or more $\mathrm{SDoH}$ is associated with lower functional capacity in primary care patients with multiple chronic conditions and suggests primary care as a fruitful setting for intervening.

\section{To see this article online, please go to: http://jabfm.org/content/ 34/4/688.full.}

\section{References}

1. National Center for Health Statistics. Health, United States, 2011: with special feature on socioeconomic status and health. Hyattsville (MD): U.S. Department of Health and Human Services; 2012.

2. Coleman-Jensen A, Rabbit M, Gregory C, Singh A. Statistical supplement to Household Food Security in the United States in 2017. Washington (DC): U.S. Department of Agriculture Economic Research Service; 2018.

3. Henry M, Watt RRL, Shivji A, Abt Associates. The 2017 annual homeless assessment report (AHAR) to Congress. Part 1: point-in-time estimates of homelessness. Washington (DC): U.S. Department of Housing and Urban Development Office of Community Planning and Development; 2017.

4. Semega J, Fontenot K, Kollar M [Internet]. Income and poverty in the United States: 2017. Census
Bureau; 2018. Available from: https://www.census. gov/library/publications/2017/demo/p60-259.html.

5. Stenholm S, Westerlund H, Head J, et al. Comorbidity and functional trajectories from midlife to old age: the Health and Retirement Study. J Gerontol A Biol Sci Med Sci 2015;70:332-8.

6. Jindai K, Nielson CM, Vorderstrasse BA, Quinones AR. Multimorbidity and functional limitations among adults 65 or older, NHANES 2005-2012. Prev Chronic Dis 2016;13:E151.

7. Charkhchi P, Fazeli Dehkordy S, Carlos RC. Housing and food insecurity, care access, and health status among the chronically ill: an analysis of the behavioral risk factor surveillance system. J Gen Intern Med 2018;33:644-50.

8. Pobutsky AM, Baker KK, Reyes-Salvail F. Investigating measures of social context on 2 population-based health surveys, Hawaii 2010-2012. Prev Chronic Dis 2015;12:E221.

9. Joint Center for Housing Studies [Internet]. The state of the nation's housing 2016. Boston: Harvard University. Available from: http://www.jchs.harvard. edu/sites/default/files/jchs_2016_state_of_the_nations_ housing_lowres_0.pdf.

10. Pan L, Sherry B, Njai R, Blanck HM. Food insecurity is associated with obesity among US adults in 12 states. J Acad Nutr Diet 2012;112:1403-9.

11. Redmond ML, Dong F, Goetz J, Jacobson LT, Collins TC. Food insecurity and peripheral arterial disease in older adult populations. J Nutr Health Aging 2016;20:989-95.

12. Seligman HK, Laraia BA, Kushel MB. Food insecurity is associated with chronic disease among lowincome NHANES participants. J Nutrition 2009; 140:304-10.

13. Seligman HK, Bindman AB, Vittinghoff E, Kanaya AM, Kushel MB. Food insecurity is associated with diabetes mellitus: results from the National Health Examination and Nutrition Examination Survey (NHANES) 1999-2002. J Gen Intern Med 2007; 22:1018-23.

14. Berkowitz SA, Seligman HK, Choudhry NK. Treat or eat: food insecurity, cost-related medication underuse, and unmet needs. Am J Med 2014; 127:303-10.

15. Gundersen C, Ziliak JP. Food insecurity and health outcomes. Health Aff (Millwood) 2015;34:1830-9.

16. Jackson JA, Branscum A, Tang A, Smit E. Food insecurity and physical functioning limitations among older U.S. adults. Preventive Medicine Reports 2019;14:100829.

17. Vozoris NT, Tarasuk VS. Household food insufficiency is associated with poorer health. J Nutr 2003;133:120-126.

18. Liu Y, Njai RS, Greenlund KJ, Chapman DP, Croft JB. Relationships between housing and food insecurity, frequent mental distress, and insufficient 
sleep among adults in 12 US states. Prev Chronic Dis 2009; 11:E37.

19. Ding M, Keiley MK, Garza KB, Duffy PA, Zizza CA. Food insecurity is associated with poor sleep outcomes among US adults. J Nutrition 2015;145:615-21.

20. Lee JS, Frongillo Jr EA. Factors associated with food insecurity among U.S. elderly persons: importance of functional impairments. J Gerontology: Series B 2001;56:S94-9.

21. Schure MB, Katon JG, Wong E, Liu CF. Food and housing insecurity and health status among U.S. adults with and without prior military service. SSM Popul Health 2016;2:244-8.

22. Muldoon KA, Duff PK, Fielden S, Anema A. Food insufficiency is associated with psychiatric morbidity in a nationally representative study of mental illness among food insecure Canadians. Social Psychiatry Psychiatric Epidemiology 2013;48:795-803.

23. Weaver LJ, Hadley C. Moving beyond hunger and nutrition: a systematic review of the evidence linking food insecurity and mental health in developing countries. Ecology Food Nutrition 2009;48:263-84.

24. DeNavas-Walt C, Proctor B, Lee CH. Income, poverty and health insurance coverage in the United States: 2005. Current Population Reports, Washington (DC): U.S. Census Bureau; 2006.

25. U.S. Department of Agriculture, Economic Research Service [Internet]. Rural economy. Available from: https://www.ers.usda.gov/data-products/agand-foodstatistics-charting-the-essentials/rural-economy/2019.

26. Coleman-Jensen A, Rabbitt MP, Gregory CA, Singh A. 2019 Household Food Security in the United States in 2018, ERR-270, U.S. Department of Agriculture, Economic Research Service.

27. Fogelholm M, Valve R, Absetz P, et al. Rural-urban differences in health and health behaviour: a baseline description of a community health-promotion programme for the elderly. Scand J Public Health 2006;34:632-40.

28. Tang WH, Topol EJ, Fan Y, et al. Prognostic value of estimated functional capacity incremental to cardiac biomarkers in stable cardiac patients. J Am Heart Assoc 2014;3:e000960.

29. Grodin JL, Hammadah M, Fan Y, Hazen SL, Tang WH. Prognostic value of estimating functional capacity with the use of the Duke Activity Status Index in stable patients with chronic heart failure. J Card Fail 2015;21:44-50.

30. Inouye SK, Peduzzi PN, Robison JT, Hughes JS, Horwitz RI, Concato J. Importance of functional measures in predicting mortality among older hospitalized patients. JAMA 1998;279:1187-93.

31. Jette M, Sidney K, Blumchen G. Metabolic equivalents (METS) in exercise testing, exercise prescription, and evaluation of functional capacity. Clin Cardiol 1990;13:555-65.
32. Hlatky MA, Boineau RE, Higginbotham MB, et al. A brief self-administered questionnaire to determine functional capacity (the Duke Activity Status Index). Am J Cardiol 1989;64:651-4.

33. Alonso J, Permanyer-Miralda G, Cascant P, Brotons C, Prieto L, Soler-Soler J. Measuring functional status of chronic coronary patients: reliability, validity and responsiveness to clinical change of the reduced version of the Duke Activity Status Index (DASI). Eur Heart J 1997;18:414-9.

34. Crocker A, Kessler R, van Eeghen C, et al. Integrating Behavioral Health and Primary Care (IBH-PC) to improve patient-centered outcomes in adults with multiple chronic medical and behavioral health conditions: study protocol for a pragmatic cluster-randomized control trial. Trials 2021;22:200.

35. Parissis JT, Nikolaou M, Birmpa D, et al. Clinical and prognostic value of Duke's Activity Status Index along with plasma B-type natriuretic peptide levels in chronic heart failure secondary to ischemic or idiopathic dilated cardiomyopathy. Am J Cardiol 2009;103:73-5.

36. Ravani P, Kilb B, Bedi H, et al. The Duke Activity Status Index in patients with chronic kidney disease: a reliability study. CJASN 2012;7:573-80.

37. Morisky DE, Green LW, Levine DM. Concurrent and predictive validity of a self-reported measure of medication adherence. Med Care 1986;24:67-74.

38. Butler DC, Petterson S, Phillips RL, Bazemore AW. Measures of social deprivation that predict health care access and need within a rational area of primary care service delivery. Health Serv Res 2013;48:539-59.

39. Rural Health Research Center (RHRC) [Internet]. Rural-urban commuting area codes (RUCAs), 2008. Available from: http://depts.washington.edu/ uwruca/.

40. Diez Roux AV, Mujahid MS, Hirsch JA, Moore K, Moore LV. The impact of neighborhoods on CV risk. Glob Heart 2016;11:353-63.

41. Kendall A, Olson CM, Frongillo EA., Jr. Relationship of hunger and food insecurity to food availability and consumption. J Am Diet Assoc 1996;96:1019-24.

42. Dixon LB, Winkleby MA, Radimer KL. Dietary intakes and serum nutrients differ between adults from food-insufficient and food-sufficient families: third National Health and Nutrition Examination Survey, 1988-1994. J Nutr 2001;131:1232-46.

43. Monsivais P, Drewnowski A. The rising cost of low-energy-density foods. J Am Diet Assoc 2007;107:2071-6.

44. To QG, Frongillo EA, Gallegos D, Moore JB. Household food insecurity is associated with less physical activity among children and adults in the U.S. population. J Nutrition 2014;144:1797-1802. 
45. Tawakol A, Osborne MT, Wang Y, et al. Stressassociated neurobiological pathway linking socioeconomic disparities to cardiovascular disease. J Am Coll Cardiol 2019;73:3243-55.

46. Core indicators of nutritional state for difficult-to-sample populations. J Nutr 1990;120:Suppl 1559-1600.

47. Kushel MB, Gupta R, Gee L, Haas JS. Housing instability and food insecurity as barriers to health care among low-income Americans. J Gen Intern Med 2006;21:71-7.

48. Phinney R, Danziger S, Pollack HA, Seefeldt K. Housing instability among current and former welfare recipients. Am J Public Health 2007;97:832-7.

49. Bailey ZD, Feldman JM, Bassett MT. How structural racism works-racist policies as a root cause of U.S. racial health inequities. $\mathrm{N}$ Engl J Med 2021;384:768-73.

50. Bailey ZD, Krieger N, Agenor M, Graves J, Linos N, Bassett MT. Structural racism and health inequities in the USA: evidence and interventions. Lancet 2017;389:1453-63.
51. Gee GC, Ford CL. Structural racism and health inequities: old issues, new directions. Du Bois Rev 2011;8:115-32.

52. Fenton. Health care's blind side: the overlooked connection between social needs and good health. Princeton (NJ): Robert Wood Johnson Foundation; 2011. Available from: http://www.rwjf.org/en/ library/research/2011/12/health-care-s-blind-side.html.

53. Baum FE, Begin M, Houweling TA, Taylor S. Changes not for the fainthearted: reorienting health care systems toward health equity through action on the social determinants of health. Am J Public Health 2009;99:1967-74.

54. Andermann A, Collaboration C. Taking action on the social determinants of health in clinical practice: a framework for health professionals. CMAJ 2016;188:E474-83.

55. Pinto AD, Bloch G. Framework for building primary care capacity to address the social determinants of health. Can Fam Physician 2017;63: e476-82. 